http:/ / dx.doi.org/10.21707/gs.v11.n01a16

\title{
CONHECIMENTO TRADICIONAL NUMA COMUNIDADE RURAL DO NORDESTE BRASILEIRO
}

\author{
Waldiléia Ferreira de Melo Batista ${ }^{1}$, Kelly Polyana Pereira dos Santos², Roseli Farias Melo de \\ BARROS $^{3}$
}

${ }^{1}$ Discentes do Programa de Pós Gradação em Desenvolvimento e Meio Ambiente, Universidade Federal do Piaui

${ }^{2}$ Docente do Departamento de Biologia, Universidade Federal do Pianí

*Autorpara correspondência: wal_bio@hotmail.com

Recebido em 24 de abril de 2016. Aceito em 12 de dezembro de 2016. Publicado em 31 de março de 2017.

Resumo - A comunidade Novo Nilo (04 24' 13" S e 42 53' 22” W) situa-se à margem direita do rio Parnaíba a uma distância de $80 \mathrm{~km}$ da capital do estado, Teresina. O estudo etnobotânico foi realizado objetivando conhecer as relações entreos moradores da referida comunidade e a vegetação local, apontando as espécies úteis e tradicionalmente utilizadas pela comunidade. Foram realizadas entrevistas semiestruturadas com 202 membros e turnê-guiada com 10 informantes-chave. O material botânico encontra-se incorporado no Herbário Graziela Barroso (TEPB) da Universidade Federal do Piauí (UFPI). Os dados quantitativos levantados foram: Valor de Uso (VU) e Fator de Consenso dos Informantes (FCI). Identificaram-se 150 espécies, distribuídas em 56 famílias e 126 gêneros. As famílias mais representativas foram Leguminosae (9,33\%) e Euphorbiaceae $(6,00 \%)$, sendo identificadas oito categorias de uso, das quais, as que obtiveram os maiores números de citações foram: medicinal (94), alimentícia (68) e ornamental (30). Attalea speciosa Mart. ex Spreng. (babaçu) foi a mais versátil, estando incluída em seis categorias de uso e apresentando VU igual 3,6, seguida por Copernicia prunifera (Mill.) H.E. Moore (carnaúba) com VU=1,96, Mangifera indica L.(manga) com 0,70, Citrus aurantium L. (laranja) com 0,58 e Lippia alba (Mill.) N. E. Br. (erva-cidreira) com 0,57. Os moradores, sobretudo as pessoas mais idosas, demonstraram conhecer e utilizar os recursos vegetais, revelando a importância desses para a sobrevivência biológica da comunidade.

Palavras-chave: Etnobotânica; Plantas Medicinais; Vegetais Úteis.

\section{Traditional KNOWLEDGE IN A RURAL COMMUNITY IN NORTHEASTERN BRAZIL}

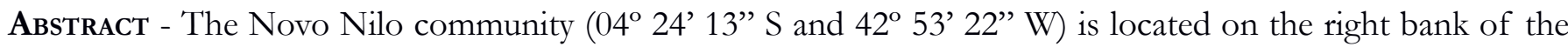
Parnaíba river at a distance of $80 \mathrm{~km}$ from Teresina, the capitalof Piauí State, Brazil. This ethnobotanical study aimed to understand the relationships between thecommunity residents and the existing vegetation, pointing out the useful and traditional species used by the community. Semi-structured interviews and guided tourswere carried out with 202 residents and10 key informants, respectively. The botanical material was deposited in the Herbarium Graziela Barroso (TEPB) of the Federal University of Piauí. The quantitative data collected were: the Use Value (VU) and the Informant Consensus Factor (ICF). A total of 150 species belonging to 56 families and 126 genera were identified. The most representative families were Leguminosae (9.33\%) and Euphorbiaceae (6.00\%), and eight use categories were identified, among them, the medicinal (94), food (68), and ornamental (30) categories had the highest numberof citation. Attalea speciosa Mart. ex Spreng. was the most versatile species, being included in six use categories and presenting VU of 3.6, followed by Copernicia prunifera (Mill.) H.E.Moore $(\mathrm{VU}=1.96)$, Mangifera indica L. (VU = 0.70), Citrus aurantium L. (VU = 0.58), and Lippia alba (Mill.) N.E. Br. (VU 
$=0.57$ ). The residents, especially elderly people, demonstrated that they knew and usedplant resources, revealing their importance for the biological survival of the community.

Keywords: Ethnobotany; Medicinal Plants; Useful Plants.

\section{Conocimiento tradicional EN UNA COMUNidAd RURAL EN EL NORESTE DE Brasil}

Resumen - La comunidad de Novo Nilo (04 24'13"S y 42 53'22'W) se ubica en la margen derecha del río Parnaíba, a una distancia de $80 \mathrm{~km}$ de Teresina, capital del estado de Piauí. El objetivo de este estudio etnobotánico fue comprender las relaciones de los residentes con la vegetación existente en la región, señalando las especies útiles y tradicionalmente utilizadas por la comunidad. Se realizaron entrevistas semiestructuradas con 202 residentes y visitas guiadas con 10 informantes clave. El material botánico se depositóen el Herbario Graziela Barroso (TEPB) de la Universidade Federal de Piaú (UFPI). Se recolectaron lossiguientes datos cuantitativos: el Valor de Uso (VU) y el Factor de Consenso de losInformantes (FCI). Se identificaron 150 especies de plantas pertenecientes a 56 familias y 126 géneros. Fabaceae (9,33\%) y Euphorbiaceae (6,00\%) fueron las familias más representativas, y se identificaron ocho categorías de uso, de las cuales, lasmás citadas fueron: medicinal (94), alimentación (68) y ornamental (30). Attalea speciosa Mart. ex Spreng. fue la especie más versátil, incluida en seis categorías de uso, presentando un VU igual a 3,6, seguida de Copernicia prunifera (Mill.) H.E. Moore (VU = 1,96), Mangifera indica L. (VU = 0,70), Citrus aurantium L. (VU =0,58) y Lippia alba (Mill.) N.E. Br. (VU = 0,57). Los residentes, especialmente las personas mayores, demostraron conocer y utilizar los recursos vegetales, revelando la importancia de éstos para la supervivencia biológica de la comunidad.

Palabras Clave: EtNobot ÁNICA; Plantas medicinales; Plantas ÚtILES

\section{INTRODUÇÃO}

A humanidade desde tempos remotos possui uma intensa relação com os recursos vegetais, quer seja para sua sobrevivência, manutenção do bem-estar físico, estético ou espiritual. Esta relação é objeto de estudo da ciência conhecida como Etnobotânica, que além deste papel, busca resgatar os aspectos culturais inseridos nas comunidades rurais, procurando compreender o estudo das sociedades humanas, passadas e presentes, e suas interações ecológicas, genéticas, evolutivas, simbólicas e culturais com as plantas (Alves et al. 2007).

A Etnobotânica tem como o objetivo a busca de conhecimento e resgate do saber botânico tradicional, particularmente relacionado ao uso dos recursos da flora (Guarim Neto et al. 2000), obtendo assim, todo entendimento possível sobre a relação de afinidade entre o ser humano e as plantas de uma comunidade (Cotton 1996).

Para Philips (1996), informações de cunho etnobotânico podem esclarecer o nível de dependência de uma comunidade em relação aos recursos vegetais locais e fornecer informações sobre as consequências de determinados tipos de exploração dos recursos.

Pesquisas nesta área facilitam a determinação de práticas apropriadas ao manejo da vegetação com finalidade utilitária, pois empregam os conhecimentos tradicionais obtidos para solucionar problemas comunitários ou para fins conservacionistas (Beck e Ortiz 1997).

Neste sentido, estes estudos têm crescido consideravelmente nas últimas décadas em muitas partes do mundo, em especial na América Latina, verificando-se muitos estudos desenvolvidos, sobretudo nas regiões Sudeste e Nordeste do Brasil, destacando-se as pesquisas realizadas por Amorozo et al. (2002), Begossi et al. 
(2002), Fonseca-Kruel e Peixoto (2004), Hanazaki et al. (2007), Coelho-Ferreira (2009), Albuquerque et al. (2010), Merétika et al. (2010) Amorozo (2012) e Albuquerque et al. (2013). No Piauí, os estudos nessa área têm crescido consideravelmente, destacando-se os trabalhos de Santos et al. (2008), Chaves e Barros (2008), Vieira et al. (2008), Aguiar e Barros (2012), Chaves e Barros (2012), Freitaset al. (2012), Sousa et al. (2012), dentre outros.

Albuquerque e Andrade (2002) afirmam que esses estudos indicam que as pessoas afetam a estrutura de comunidades vegetais e paisagens, a evolução de espécies individuais, a biologia de determinadas populações de plantas de interesse, não apenas sob aspectos negativos como comumente se credita à intervenção humana, mas beneficiando e promovendo os recursos manejados.

Com base nessas considerações, desenvolveu-se um estudo de cunho etnobotânico e objetivou-se identificar as espécies botânicas utilizadas pela população dessa comunidade e suas devidas aplicabilidades, distribuindo-as em categorias de uso; reconhecer quais espécies da flora citadas pela comunidade são utilizadas na geração de renda e verificar a distribuição do saber popular tradicional por gênero e faixa etária.

\section{Material e métodos}

\section{Caracterização da área de estudo}

O município de União, localizado no estado do Piauí, situa-se à margem direita do rio Parnaíba com sede nas coordenadas $04^{\circ} 35^{\prime} 09^{\prime}$ ' S e 42 $51^{\circ}$ '51" W, a uma distância de $59 \mathrm{~km}$ da capital do estado, Teresina. Limitase ao sul com Miguel Alves e Cabeceiras do Piauí, ao norte e leste com Lagoa Alegre e José de Freitas e a oeste com rio Parnaíba/ estado do Maranhão (IBGE 2010). Encontra-se a uma altitude de 52 metros acima do nível do mar (CEPRO 2011) e possui clima Tropical Quente com uma vegetação de transição entre Cerrado e Mata dos Cocais. Apresenta uma população estimada em 42.654 habitantes e uma área territorial de $1.173 \mathrm{~km}^{2}$ onde se encontra a comunidade rural Novo Nilo (IBGE 2010).

A referida comunidade foi criada pelo coronel Gervásio Costa na década de 1920, onde instalou uma fábrica de beneficiamento de coco babaçu (Attalea speciosa Mart. ex Spreng.) para a produção de óleo e sabão. Dista aproximadamente $80 \mathrm{~km}$ da capital tendo seus limites com os seguintes povoados circunvizinhos: ao norte, localidade Bebedouro, ao oeste com Varginha, ao Leste com Pedrinhas e a sul com rio Parnaíba/ estado do Maranhão, cuja sede situa-se nas coordenadas 04 24' 13" S e 42 53' 22” W (IBGE 2010), como mostrado na Fig. 1.

\section{Coleta e análise dos dados}

A comunidade possui uma população aproximada de 1.516 habitantes, em sua maioria, lavradores e pescadores, distribuídos em 371 famílias. Das quais se definiu o total de 54,4 \% delas como universo amostral da pesquisa para os levantamentos etnobotânicos, socioeconômicos e culturais, perfazendo 202 entrevistas, seguindo o preconizado por Begossi et al. (2004) que afirmam ser uma amostra representativa em comunidades com mais de 50 pessoas a proporção de $25 \%$ a $80 \%$.

Os dados foram coletados após submissão e aprovação do projeto de pesquisa no Comitê de Ética e Pesquisa da Universidade Federal do Piauí. As entrevistas foram realizadas mediante permissão dos entrevistados 
no aceite, conhecimento e assinatura do Termo de Consentimento Livre e Esclarecido (TCLE), em duas vias, uma pertencente ao entrevistado e outra ao pesquisador, as quais foram realizadas entre os meses de julho de 2012 a julho de 2013, por meio de observação direta e com o auxílio de formulário padronizado com questões abertas e fechadas, por meio de entrevistas semiestruturadas (Bernard 1988), apresentando a seguinte estrutura: identificação, localização e dados socioeconômicos (composição familiar, idade, gênero, escolaridade, renda, habitação, saneamento, informações místico-religiosas e etnobotânicas).

Figura 1 - Localização da Comunidade Novo Nilo, União, Piauí/Brasil.

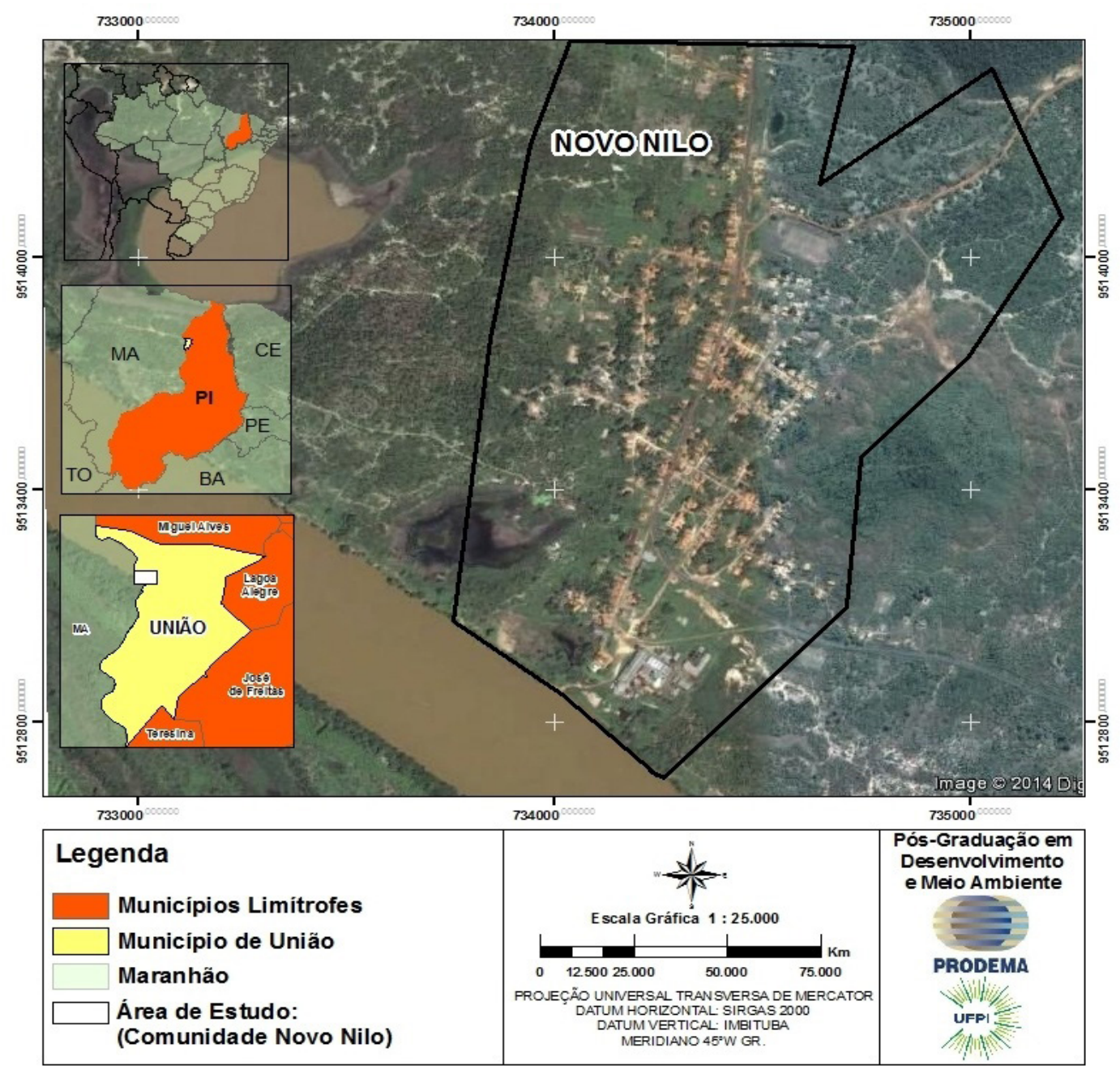

Fonte: Adaptado de IBGE (2010), através do Software ArcGIS (2.3)

Adotou-se a técnica de amostragem e seleção de informantes, denominada "bola de neve" (Bailey 1994), que consiste em conversar com algumas pessoas da comunidade em seus domicílios e durante as entrevistas, estas indicaram outras pessoas a serem entrevistadas. Do total de habitantes, 30 foram indicados como conhecedores da vegetação local e suas finalidades, e destes, 10 informantes-chave, com os quais foi realizada a técnica de turnêguiada (Bernard 1988). A coleta e herborização do material botânico foram realizadas segundo a metodologia preconizada por Mori et al. (1989), e após a herborização, todo o material foi incorporado ao acervo do Herbário Graziela Barroso (TEPB) da Universidade Federal do Piauí. As identificações das espécies foram realizadas tomando como referência a bibliografia especializada e comparações com exsicatas identificadas. O sistema adotado foi o de Cronquist (1981), com exceção da família Leguminosae que obedeceu a Judd et al. (1999). 
As abreviaturas dos nomes dos autores e as grafias das espécies estão de acordo com os sítios do MOBOT (mobot.mobot.org/W3T/Search/vast.html) e IPNI (www.ipni.org). As indicações foram agrupadas com base nas categorias de uso propostas por Lima et al. (2000).

Para calcular o Valor de Uso (VU) atribuído às espécies, utilizou-se a metodologia proposta por Phillips e Gentry (1993a e b), modificado por Lucena et al. (2012), que atribui a essa técnica a seguinte fórmula: VU $=\Sigma \mathrm{U} / \mathrm{n}$, onde $\mathrm{U}=$ número de citações da etnoespécie por informante e $\mathrm{n}=$ número total de informantes. Para categoria medicinal, as informações obtidas foram agrupadas segundo a classificação das doenças da Organização Mundial da Saúde (OMS 2000) e calculado o Fator de Consenso dos Informantes (FCI) de acordo com Trotter e Logan (1986) pela fórmula FCI = nur - nt / nur - 1, onde nur é o número de citações de usos em cada categoria da OMS (2000) e nt, o número de espécies usadas.

Após a realização das entrevistas, estas foram transcritas em laboratório, juntamente com os dados referentes às conversas, discussões e debates informais registrados em diário de campo, além do registro fotográfico das práticas sociais, econômicas, culturais, ambientais e grande variedade de espécies vegetais. As respostas foram tabuladas em tabelas e gráficos, e analisadas por meio de estatística descritiva básica, com o objetivo de valorizar o conhecimento tradicional local e uso sustentável dessa vegetação.

\section{RESUltados E Discussão}

Em Novo Nilo as plantas fazem parte da rotina dos moradores para diversos fins, principalmente nas categorias Medicinal, Alimentícia, Ornamental, Construção, Forrageira, Místico-religioso, Energética, e Artesanal. A base econômica está voltada para a agricultura, com a prática de cultivos em roça e extração vegetal, principalmente do babaçu (Attalea speciosa Mart. ex Spreng) e da carnaúba (Copernicia prunifera (Mill.) H.E.Moore).

Os produtos gerados da produção agrícola são direcionados para o consumo, e em alguns casos, o excedente dessa produção é comercializado. Um total de 150 espécies foram citadas, identificadas e distribuídas em 126 gêneros e 56 famílias botânicas (Tab. 1). As famílias mais representativas em número de espécies foram: Leguminosae (9,33 \%), Euphorbiaceae (6,00 \%), Lamiaceae (4,67\%), Arecaceae, Anacardiaceae, Apocynaceae e Rutaceae (4,00 \% cada), Curcubitaceae e Convolvulaceae (3,33\%), como demonstrado na Fig. 2. Das 69 famílias botânicas, Agavaceae, Asparagaceae, Bixaceae, Bromeliaceae, Caricaceae, Caryocaraceae, Cecropiaceae, Crassulaceae, Iridaceae, Lauraceae, Lecythidaceae, Melastomataceae, Meliaceae, Moraceae, Musaceae, Olacaceae, Oxalidaceae, Passifloraceae, Phytolacaceae, Piperaceae, Portulacaceae, Punicaceae, Rosaceae, Scrophulariaceae, Tiliaceae e Turneraceae, foram representadas por apenas uma espécie.

Após a análise das espécies citadas, estas foram distribuídas em oito categorias de usos: Medicinal (62 \%), Alimentícia (45,33\%), Ornamental (20\%), Construção (10\%), Forrageira (6 \%), Místico-religioso (5,33 \%), Energética (4,33 \%) e Artesanal (2\%). As espécies mais versáteis foram: babaçu (Attalea speciosa Mart. ex Spreng) e da carnaúba (Copernicia prunifera (Mill.) que alcançaram seis e cinco categorias de usos, respectivamente. Essa multiplicidade de usos para babaçu corrobora o observado por Rufino et al. (2008) em Buíque, PE e Gonzalez-Perez et al. (2012) na Terra Indígena Las Casas, PA. Quanto à versatilidade da carnaúba, fato por demais discutido nacionalmente, vale ressaltar o destaque mencionado pelos estudos etnobotânicos realizados no Piauí que trazem esta realidade, como Amorim (2010) e Sousa (2012). 
Figura 2 - Famílias botânicas mais representativas em número de espécies na Comunidade Novo Nilo, União, Piauí. (Fonte: pesquisa direta, setembro/2013).

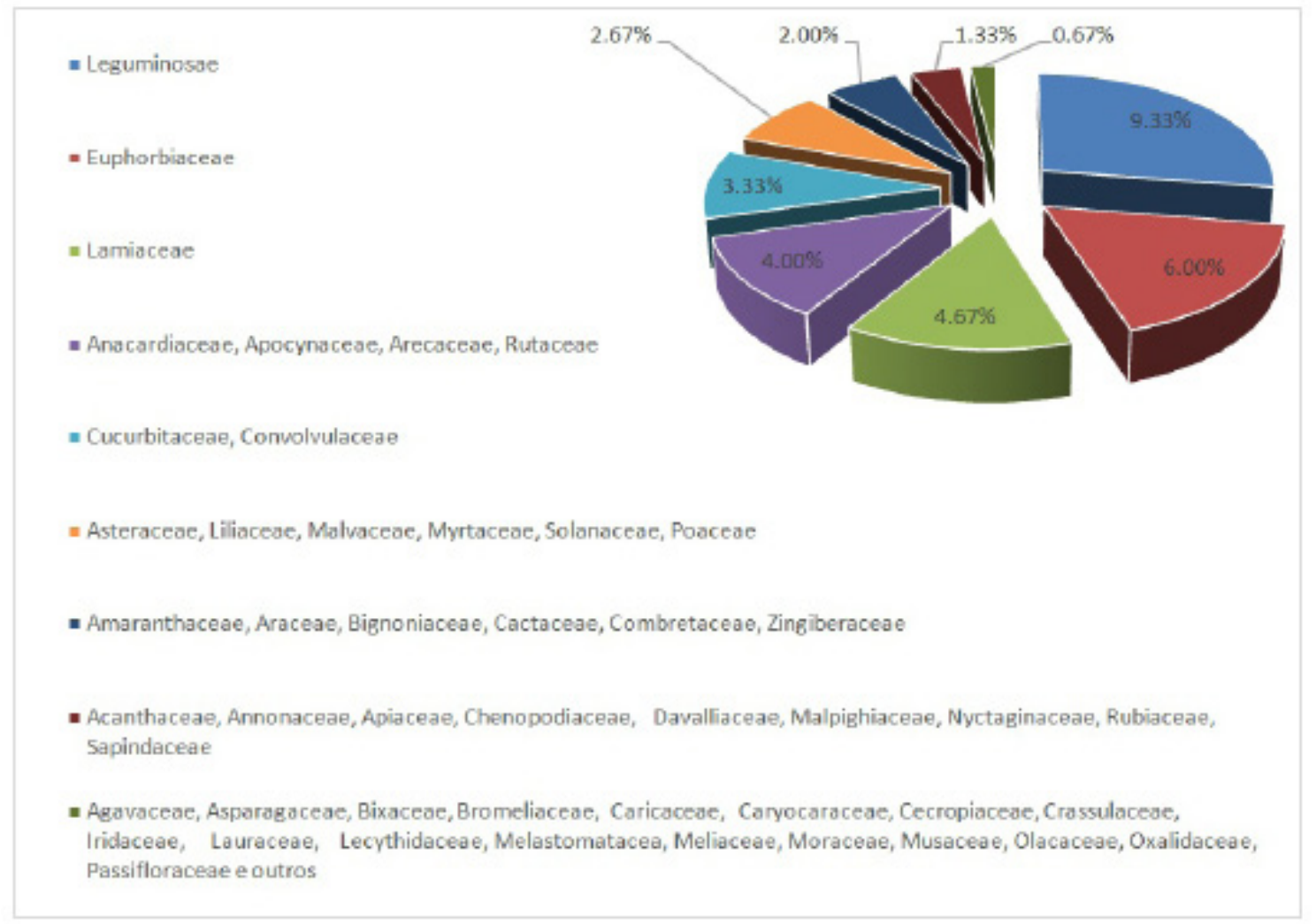

Tabela 1 - Lista das espécies utilizadas na Comunidade Novo Nilo, União/PI. Legenda: NV = Nome Vulgar; HAB = Hábito: erv = erva; sub = subarbusto; arb = arbusto; arv = árvore; trep $=$ trepadeira; $\mathrm{ST}=$ Status: $\mathrm{e}=\mathrm{exótica;} \mathrm{n}=\mathrm{nativa}$. $\mathrm{NC}=$ número de coletor (il - identificada no local, não coletada); $\mathrm{VU}=$ valor de uso; Categorias de Uso = Cat.U: $\mathrm{a}=$ medicinal; $\mathrm{b}=$ alimentação humana; $\mathrm{c}=$ construção; $\mathrm{d}=$ produção energética; $\mathrm{e}=$ forrageira; $\mathrm{f}=$ artesanal; $\mathrm{g}=$ místicoreligiosa; $h=$ ornamental.

\begin{tabular}{llllllll}
\hline Família/espécie & NV & HAB & ST & NC & VU & Cat. U \\
\hline
\end{tabular}

\section{Acanthaceae}

Justicia pectoralis Jacq.

Anador

erv $n$

29.795

0,03

a

Justicia pectoralis var. stenophylla

Leonard

Trevo

erv

n

29.836

0,02

a,g

\section{Agavaceae}

Sansevieria trifasciata Prain

erv

e

29.807

0,08

h,g

\section{Amaranthaceae}

Alternanthera dentata (Moen-

ch) Scheygr.

Penicilina

Bredo

Amaranthus deflexus L.

Gomphrena globosa L.

Perpeta erv

erv

erv

n

29.837

0,01

a

e

il

0,03

a,e

$\begin{array}{llll}\text { e } & 29.853 \quad 0,01 \quad \text { a }\end{array}$

\section{Anacardiaceae}




\begin{tabular}{lcccccc}
\hline Anacardium occidentale L. & Caju & arv & $\mathrm{n}$ & 29.794 & 0,44 & a,b,e \\
$\begin{array}{l}\text { Mangifera indica L. } \\
\text { Myracrodruon urundewva M.Alle- }\end{array}$ & Manga & arv & $\mathrm{e}$ & 29.747 & 0,70 & a,b \\
mão & Aroeira & arv & $\mathrm{n}$ & 29.792 & 0,07 & a,c \\
Spondias lutea L. & Cajá & arv & $\mathrm{n}$ & 29.753 & 0,11 & a,b
\end{tabular}

\section{Anacardiaceae}

Spondias purpurea L.

Siriguela

$\operatorname{arv}$

$$
\text { n }
$$

$29.814 \quad 0,23$

$a, b$

Spondias tuberosa Arr. Cam.

Umbu

$\operatorname{arv}$

n

29.791

$0,03 \quad b$

\section{Annonaceae}

Annona muricata L.

Annona squamosa $\mathrm{L}$.

\section{Apiaceae}

Coriandrum sativum L.

Foeniculun vulgari Mill.

\section{Apocynaceae}

Allamanda blanchetti A.DC.

Pente-de-macaco

Allamanda cathartica L.

Plumeria Alba L.

Cálice-de-ouro

\section{Apocynaceae}

Catharanthus roseus (L.) G. Don

Nerium oleander L.

Thevetia peruviana (Pers.) Merr.

\section{Araceae}

Caladium bicolor Vent.

Dieffenbachia picta (Lodd)

Schott

Syngonium podophyllum Schott.

\begin{tabular}{|c|c|c|c|c|}
\hline Pica-pau & erv & e & 29.835 & 0,15 \\
\hline $\begin{array}{l}\text { Comigo-ninguém- } \\
\text { pode }\end{array}$ & erv & $\mathrm{n}$ & il & 0,33 \\
\hline Agave & erv & e & il & 0,01 \\
\hline
\end{tabular}

\section{Arecaceae}

Astrocaryum vulgare Mart.

Attalea speciosa Mart. ex

Spreng

Cocos nucifera L.

Copernicia prunifera (Mill.) $\mathrm{H}$.

E. Moore

Tucum

Babaçu

Coco-da-praia

Carnaúba

Açaí
Graviola

Ata

Jasmim

arb

arb

erv

erv

arb

arb

arb

$\mathrm{n}$

29.855

0,02

29.753

0,35

a,b

$a, b$

Coentro
Erva-doce

29.819

0,35

b

e

29.851

0,03

a,b
Euterpe oleracea Mart. arv

n

il

0,07

$a, b, e, f$

arv

arv

n

il

3,63

a,b,c,d,e,f

e

il

0,40

$\mathrm{a}, \mathrm{b}, \mathrm{h}$

arv

n

il

1,96

a,b,c,e,f

arv

n

29.828

b 
Mauritia flexuosa L. f.

Asparagaceae

Asparagus SP

Milindro

erv

29.782

0,03

a

\section{Asteraceae}

Helianthus annuus L.

Girassol

sub

Alface

Lactuca sativa L.

Pingo-de-ouro

erv

29.823

$0,03 \quad \mathrm{~h}$

Melampodium divaricatum DC.

Tagetes erecta L.

Cravim

erv

e

29.858

$0,01 \quad b$

\section{Bignoniaceae}

Jacaranda brasiliana Pers.

Caroba

erv

erv

29.846

0,07

h

Handroanthus serratifolius

Pau-d'arco-amarelo

$\operatorname{arv}$

e

29.802

0,01

a

Tecoma stans (L.) Juss. ex Kunth

Ipezinho

arb

e

29.799

0,01

h

\section{Bixaceae}

Bixa orellana $\mathrm{L}$.

Urucum

$\operatorname{arb}$

n

29.749

0,02

a,b

\section{Bromeliaceae}

Ananas comosus (L.) Merr.

Abacaxi

erv

n

il

0,02

b

Mandacaru

arb

Coroa-de-frade

Melocactus zehnt
Rose) Luetzelb.

Rosa-madeira

Mamão

arv

erv

arb

\section{Caricaceae}

Carica papaya L.

\section{Caryocaraceae}

Caryocar coriaceum Wittm.

Pequi

arv

Embaúba

arv
n

il

0,01

a,c

\section{Chenopodiaceae}

Beta vulgaris L.

Beterraba

Chenopodium ambrosioides L. erv

sub
29.850

29.789

28.856

0,01

h

Mastruz

Combretaceae 
Combretum duarteanum Cam-

bess.

Combretum leprosum Mart.

Terminalia catappa $\mathrm{L}$.

\section{Convolvulaceae}

Ipomoea batatas(L.) Lan.

Ipomoea quamoclit $\mathrm{L}$.

Ipomoeaasarifolia (Desr.)

Roem \& Schult

Ipomoea SP

Operculina macrocarpa (L.)

Farw.

\section{Crassulaceae}

Bryophyllum pinnatum (Lam.)

Oken

\section{Cucurbitaceae}

Curcubita pepo L.

Citrullus vulgaris Schrad. ex

Ecml. \& Zeyh.

Cucumis anguria $L$.

Curcubita sativus L.

Mormodica charantia L.

\section{Davalliaceae}

Nephrolepis biserrata Schott

Nephrolepis exaltata Schott

\section{Euphorbiaceae}

Cnidoscolus loefgrenï $\mathrm{Pax} \& \mathrm{~K}$. Hoffm.

Croton campestris A. St. Hil.

\section{Euphorbiaceae}

Euphorbia milii Des. Moul.

Euphorbia tirucalli Forssk. Jatropha gossypiifolia L.

Jatropha ribifolia (Pohl) Baill. Manihot utilissima Pohl.

Manihot esculenta Crantz

Phyllanthus niruri $\mathrm{L}$.

Catinga-branca

Mufumbo

Amêndoa

Batata-doce

Primavera

Salsa

Jitirana

Batata-de-purga

Folha-santa

erv

e

29.817

0,15

a

$\begin{array}{cccccc}\text { Abóbora } & \text { sub esc } & \text { E } & 29.818 & 0,26 & \text { a,b } \\ \text { Melancia } & \text { sub esc } & \text { e } & 29.825 & 0,28 & \text { b } \\ \text { Maxixe } & \text { sub esc } & \text { e } & 29.838 & 0,33 & \text { b } \\ \text { Pepino } & \text { erv } & \text { e } & \text { il } & 0,11 & \text { b } \\ \text { Melão-de-são caetano } & \text { sub esc } & \text { n } & 29.843 & 0,04 & \text { a,b,e }\end{array}$

Rabo-de-peixe

Samambaia-de- metro erv

erv
Cancanção-branco

Velame sub

sub
29.763

29.760
$0,09 \quad \mathrm{~h}$

$29.815 \quad 0,09 \quad \mathrm{~h}$

Coroa-de-cristo
Cachorro-pelado
Pião-roxo
Pião-branco
Macaxeira
Mandioca
Quebra-pedra

erv

arb

arb

arb

sub

sub

erv
29.848

29.860

29.759

29.761

il

il

29.786
0,03

0,12

a 


\section{Lamiaceae}

Lippia alba (Mill.) N. E. Br.

Lippia gracillis Humb.,Bonpl\&

Kunth.

Mentha arvensis L.

Mentha x villosa Huds

Ocimum gratissimum L.

Plechtranthus amboinicus (Lour.) Spreng.

Plechtranthus barbatus Andrews

\section{Lauraceae}

Persea americana Mill.

\section{Lecythidaceae}

Lecythis pisonis Cambess.

\section{Leguminosae}

\section{Caesalpinoidae}

Baubinia ungulata L.

Libidibia ferrea (Mart. ex Tul.)

L.P.Queiroz

Delonix regia (Boj. ex Hook)

Raf.

Hymenaea courbaril L.

Senna obtusifolia (L.) H. S.

Irwin \& Barneby

Senna occidentalis (L.) Link

\section{Leguminosae Mimosoidae}

Albizia niopoides (Spruce ex Benth.) Burkart.

Mimosa caesalpiniifolia Benth.

Anadenanthera colubrina (Vell.)

Brenan

Vachellia farnesiana (L.) Wight \& Arn

\section{Leguminosae}

\section{Papilionoidae}

Amburana cearensis (Allemão)

A.C.Sm.

Andira retusa Humb.,Bonpl. \& Kunth

Phaseolus vulgaris L
Emburana

Erva-cidreira
Alecrim
Vick
Hortelã
Manjericão

Malva-do-reino

Boldo

Abacate

Sapucaia

Mororó

Jucá

Flamboiant

Jatobá

Matapasto

Fedegoso

Angico-branco

Unha-de-gato

Angico-preto

Coronha

Angelim

Feijão sub

sub

erv

erv

sub

erv

e

29.781

0,20

29.839

0,51

erv

e

(2)

arv

e

il

0,03

a,b

$\operatorname{arv}$

n

il

0,01

b,c

$\operatorname{arv}$

arv

n

29.779

0,02

a

$29.780 \quad 0,01 \quad$ a,c

arb

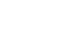

29.803

$0,03 \quad \mathrm{~h}$

$\operatorname{arv}$

29.829

0,03

a,c

sub

il

0,01

a,e

sub

29.752

0,02

a

$\operatorname{arv} \quad \mathrm{n} \quad 29.861 \quad 0,05 \quad$ a,c,d

arv $\quad \mathrm{n} \quad 29.830 \quad 0,53 \quad$ a,c,d,e

$\operatorname{arv} \quad \mathrm{n} \quad 29.842 \quad 0,03 \quad$ a,d

arv

n

il

$0,01 \quad a$ 


\section{Liliaceae}

Allium cepa L.

Allium sativum L.

Allium schoenoprasum L.

Aloe vera (L.) Burm. f.

Byrsonima crassifolia (L.) Kunth

Malpighia glabra L.

\section{Malvaceae}

Abelmoschus esculentus Moench

$$
\text { Quiabo }
$$

Gossypium herbaceum L.

Hibiscus rosa-sinensis $\mathrm{L}$.

Sida glomerata Cav.

\section{Melastomataceae}

Mouriri samanensis Urb.

\section{Meliaceae}

Aqadirachta indica A. Juss.

\section{Moraceae}

Artocarpus integrifolia L. $\mathrm{f}$.

\section{Musaceae}

Musa paradisiaca L.

\section{Myrtaceae}

Eucalyptus globulus Labill.

Campomanesia aromatica (Aubl.)

Griseb

Psidium guajava L.

Syzygium jambolanum (Lam.)

DC.

Algodão
Margarida
Relógio

Cebola
Alho
Cebolinha
Babosa
Murici
Acerola

erv

erv

erv

erv

arb

$\operatorname{arb}$

sub

arb

arb

sub

Crioli

Ninho

Jaca

Banana

\section{Eucalipto}

Guabiraba

Goiaba

Azeitona-preta

\section{Nyctaginaceae}

arv

$\operatorname{arv}$

$\operatorname{arv}$

erv

arv

arb

arv

arv
Bougainvillea glabra Choisy

Mirabilis jalapa L.

\section{Olacaceae}

Ximenia americana L.

Ameixa

Carambola

$$
\begin{gathered}
\text { Buganville } \\
\text { Bunina }
\end{gathered}
$$

\section{Oxalidaceae}

Averrhoa carambola L.

$\begin{array}{ccccc}\text { erv } & \text { e } & \text { il } & 0,01 & \text { a,b } \\ \text { erv } & \text { e } & \text { il } & 0,06 & \text { a,b } \\ \text { erv } & \text { e } & 29.822 & 0,37 & \text { a,b } \\ \operatorname{erv} & \text { e } & 29.849 & 0,09 & \text { a } \\ \operatorname{arb} & \text { n } & 29.755 & 0,04 & \text { b } \\ \operatorname{arb} & \text { e } & 29.821 & 0,55 & \text { a,b }\end{array}$

$$
\text { n }
$$

29.816

0,12

b

$$
\text { e }
$$

29.746

0,12

a,h

$$
\text { e }
$$

il

0,03

$a, b$

e

29.827

0,33

$a, b$

e

il

0,01

a,b

n

il

0,01

$a, b$

n

29.776

0,39 a,b

e

29.854

0,01 a,b

\section{Passifloraceae}

Passiflora edulis Sims.

Maracujá

sub esc.

n $\quad 29.774$

0,03

$a, b$ 
Phytolacaceae

Petiveria alliacea $\mathrm{L}$.

Piperaceae

Piper tuberculatum Jacq.

Pimenta-de-macaco

Cymbopogon citratus (DC.) Sta$\mathrm{ph}$

Oryza sativa L.

Saccharum officinarum L.

Zea mays L.

Portulacaceae

Portulaca gradiflora Hook.

\section{Punicaceae}

Punica granatum L.

\section{Rosaceae}

Rosa chinensis Jacq.

\section{Rutaceae}

Citrus aurantifolia (Christm.)

Swingle

Citrus aurantium L.

Citrus limonum Risso

Citrus medica L.

Citrus reticulata Blanco

Ruta graveolens L.

\section{Rubiaceae}

Genipa americana L.

Morinda citrifolia $\mathrm{L}$.

\section{Sapindaceae}

Cardiospermum anomalum Cambess

Talisia esculenta Radlk.

\section{Scrophulariaceae}

Scoparia dulcis L.

\section{Solanaceae}

Capsicum annuum L.

Capsicum chinense Jacq.

Capsicum frutescens L. sub

Capim-santo

Tipi

sub

Arroz

Cana-de-açucar

Milho

Nove-horas

Romã

Roseira

Limão-galego

Laranja

Limão-azedo

Limão-doce

Tangerina

Arruda

Jenipapo

None

Cedro-branco

Pitomba

Vassourinha

Pimentão

Pimenta-de-cheiro

Pimenta- malageta

erv

erv

sub

sub

erv

arb

sub

arb arb

arb

arb

arb

erv

arv

arv

arv

$\operatorname{arv}$

sub

sub

sub

sub n

29.841

0,0

e

29.805

0,06

a

e

29.824

0,13

h$$
\text { e }
$$$$
\text { il }
$$$$
0,03
$$$$
a, b
$$$$
\text { e } 29.751
$$$$
0,58
$$$$
\text { a,b }
$$$$
\text { e } 29.757
$$

0,26

a,b

e $\quad 29.810$

0,16

a,b

e Il

e 29.826

0,08

b

$0,04 \quad a, g$

$$
\text { n } 29.772
$$

0,01 b,d

e

29.748

0,22

a

n $\quad 29.778$

0,03

c

$\begin{array}{llll}\text { n } & 29.847 & 0,03 \quad \text { b }\end{array}$

$\mathrm{n}$

29.787

0,41

$a, g$

e $\quad 29.811$

0,13

b

e $\quad 29.812$

0,20

b

e $\quad 29.766$

0,20 b,g 
Lycopersicon esculentum Mill.

\section{Tiliaceae}

Luebea speciosa Willd.

Açoita-cavalo

Chanana

Turneraceae

Turnera ulmifolia $\mathrm{L}$.
Tomate sub

arv

sub
Jardineira

Açafrão

Gengibre

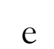

29.767

0,08

\section{Zingiberaceae}

Alpinia nutans (L.) Rosc.

Crocus sativus L.

Zingiber officinale Roscoe

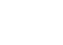

$\mathrm{n}$
29.777

0,04

n $29.7642 \quad 0,10 \quad$ a

As espécies identificadas distribuem-se nos seguintes hábitos: herbáceo (30\%), subarbustivo (19,3\%), arbustivo (20,7 \%), subarbustivo escandente (3,3\%) e arbóreo (26,7 \%). Do total, $48 \%$ são nativas e $52 \%$ são exóticas. Estas últimas são encontradas em diversos ambientes, principalmente nos quintais, que apresentam importância significativa na comunidade. Verificando-se, portanto, a predominância dessas espécies, resultado também observado por Amaral e Guarim Neto (2008) em quintais de Rosário Oeste/MT e por Carniello et al. (2010) em Mirassol D’ Oeste/MT. A superioridade da representação das espécies exóticas deve-se ao fato de que as categorias predominantes foram aquelas de plantas cultivadas em quintais, que geralmente são introduzidas. A predominância dessas espécies indica a influência das tradições europeia e africana, conforme constatado também por Pilla, Amorozo e Furlan (2006). Porém, os resultados foram discordantes dos verificados por Vieira (2008), Souza (2012), Borges e Peixoto (2009), Crepaldi e Peixoto (2010) e Lopes e Lobão (2013). Embora a significativa representatividade das plantas nativas demonstre que a população apresenta um elevado conhecimento sobre o uso de diversas plantas.

Quanto à distribuição do conhecimento em relação ao gênero, verificou-se uma proporção razoavelmente equilibrada, porém as mulheres citaram $58 \%$ das espécies e os homens $42 \%$. Essa diferença se dá, provavelmente porque as mulheres têm um maior domínio das espécies cultivadas próximo às residências, utilizadas principalmente como medicinais, alimentícias e ornamentais. Ceolin et al. (2010) afirmam a predominância do gênero feminino evidenciando a importância das mulheres na transmissão do conhecimento entre as gerações, dados também verificados por diversos autores (Almeida 2000, Winklerprins 2002, Rondon Neto et al. 2004, Rosa et al. 2007 e Vieira et al. 2007). Na análise quanto ao saber por faixa etária, idosos têm maior conhecimento que adultos e jovens. Isso mostra, de acordo com Zuchiwschi et al. (2010) a correlação entre uso de espécies e conhecimento; e as diferenças entre as gerações. No que concerne ao repasse do conhecimento, 90 \% dos entrevistados afirmam ter adquirido dos pais, avós, parentes e pessoas mais velhas da comunidade. Verificou-se ainda, que este ocorre oralmente durante realização de afazeres domésticos coletivos, trocas de experiências nas conversas dos terreiros entre os vizinhos, em atividades realizadas entre grupos de trabalho e, sobretudo durante conversas cotidianas entre filhos, pais e avós no seio familiar. Amorozo (2012) aponta que, em comunidades rurais, esse conhecimento é transmitido desde muito cedo, a partir do momento em que as crianças começam a acompanhar os adultos nas tarefas cotidianas do campo, e que dessa forma vão se habituando a plantar e 
raramente se desfazem de tal atividade, mesmo migrando para áreas urbanas. Além da transmissão vertical, também foi observada a transmissão horizontal, que se dá principalmente entre vizinhos que trocam mudas de plantas e receitas caseiras, levando ao conhecimento e uso de novas espécies em seu repertório. Essa troca, segundo Baldauf et al. (2009) leva à incorporação de novas plantas por parte dos sujeitos envolvidos nela. Além disso, reforça laços sociais e contribui para a manutenção desse conhecimento na comunidade.

Observamos na Fig. 3 que a categoria de uso que apresentou o maior número de espécies citadas foi a medicinal (94), seguida da alimentação humana (68), ornamental (30), construção (15), forrageira (9), místicoreligiosa (8), produção energética (7) e artesanal (3).

Figura 3 - Números de espécies botânicas indicadas por categorias de uso na comunidade Novo Nilo, União/PI. (Fonte: pesquisa direta, setembro/2013).

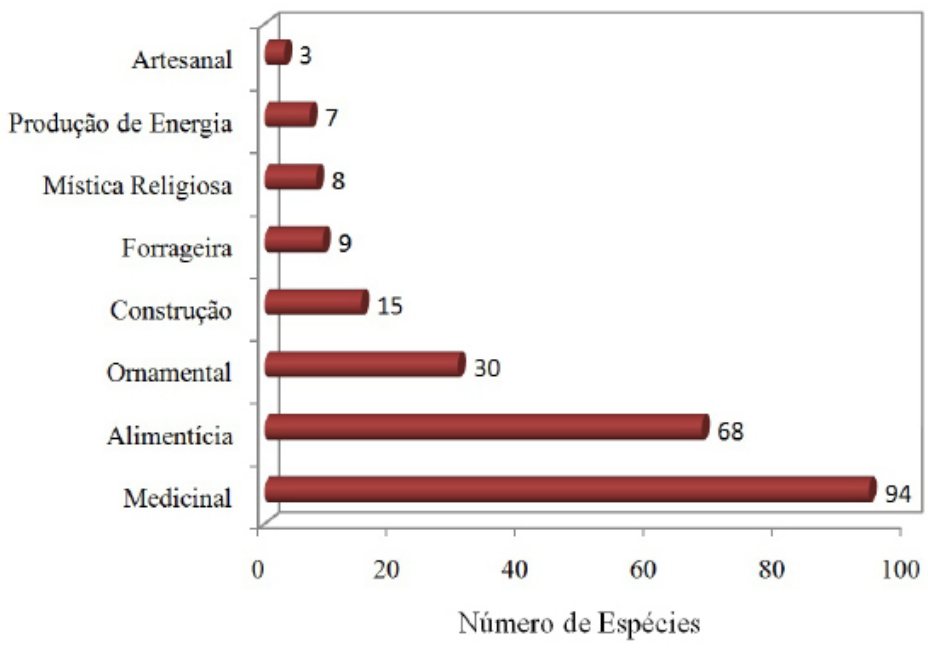

Do número total de plantas identificadas, 32 foram referidas exclusivamente para categoria de uso medicinal, 33 para categoria medicinal e alimentícia, 26 exclusivamente ornamentais, sete para medicinal e construção, cinco para medicinal e mística, duas para mística e ornamental, duas para medicinal e forrageira, uma para construção e produção energética e outra para construção e alimentícia. Somente uma planta foi citada para seis das oito categorias estudadas.

Medicinal - representada por 94 espécies, distribuídas em 43 famílias botânicas e 81 gêneros, demonstrou que a utilização de plantas para fins terapêuticos se constitui como elemento cultural bastante expressivo na comunidade rural Novo Nilo, por ser considerado mais eficiente e acessível financeiramente. As famílias mais representadas foram: Leguminosae (12 espécies), Lamiaceae (7) e Euphorbiaceae (6). Considerando apenas a família Leguminosae resultado similar foi observado por Aguiar (2009) e segundo Souza (2007), o destaque para Leguminosae entre as plantas de uso medicinal pode ser explicado pelo grande número e diversidade de espécies que compõem esta família. Quanto a família Lamiaceae, Oliveira e Menini Neto (2012) e Carvalho et al. (2013) constataram dados semelhantes. As espécies medicinais levantadas nas áreas corresponderam a 62,6 $\%$ do total, corroborando com Figueiredo et al. (1993), Rossato et al. (1999), Pasa et al. (2005) Vieira et al. (2008) e Gandolfo e Hanazaki (2011) que referiram a categoria medicinal com o maior número de espécies e citações. Em Novo Nilo, tal fato justifica-se pela confiabilidade da comunidade em remédios caseiros associada à disponibilidade dessas plantas nos próprios quintais e à dificuldade de acesso à assistência médica. Simões et al. (1998) explica que o alto custo dos medicamentos industrializados, o difícil acesso da população à assistência médica, bem como a tendência ao uso de produtos de origem natural justifica o aumento da utilização de plantas 
medicinais. Quanto à aquisição das plantas, isso ocorre no quintal da própria casa, de vizinhos ou parentes e nas matas. Resultados semelhantes foram observados por Mosca e Loiola (2009), Oliveira et al. (2010), Marinho et al. (2011).

As espécies que mais se destacaram em número de citações nessa categoria foram: erva-cidreira (Lippia alba (Mill.) N. E. Br.), o boldo (Plectranthus barbatus Andr.), o mastruz (Chenopodium ambrosioides L.) e o capim-santo (Cymbopogon citratus Stapf.). Oliveira et al.(2010) em São Domingos do Capim/PA, verificaram que a erva-cidreira se destacou pelo elevado valor de importância relativa.

Em relação aos modos de preparos informados pelos moradores, há uma grande preferência no uso na forma de chá (decocto ou infusão), que obteve 49,63\% das indicações, seguida pela garrafada $(24,10 \%)$, lambedor (10,21 \%), maceração (7,30\%), banho e suco (3,65\% cada) e emplastos (1,46\%). Quanto a primazia dos chás, o mesmo foi referido por diversos autores como Mosca e Loiola (2009), Caicó/RN, Oliveira et al. (2010) nas comunidades rurais de Oeiras/PI, Albertasse et al. (2010) em Vila Velha/ ES e Costa e Mayworm (2011) em Extrema/MG. Isso se verifica provavelmente pela facilidade de preparo e rapidez do suposto efeito. Como partes mais utilizadas destacaram-se as folhas (50\%), pois estas estão disponíveis o ano inteiro em razão das formações vegetais da região não apresentarem caducifolia. Seguidas a estas se destacaram as cascas (19,23 $\%)$, frutos $(13,08 \%)$ raízes e sementes $(5,38 \%$ cada), caules $(3,84 \%)$, e resinas $(3,09 \%)$, corroborando com os resultados obtidos por Agra et al. (2007) no Cariri/PB, De La Cruz et al. (2007) nos Andes peruanos e Pasa (2011) na comunidade Jardim, Cuiabá/MT.

No que se refere ao consenso dos informantes da comunidade, quanto à potencialidade das espécies de plantas citadas, apresentou-se 13 categorias de doenças e dentre essas, houve maior concordância entre os entrevistados, para aquelas indicações relativas ao tratamento das doenças do sistema nervoso $(0,93)$. Resultado semelhante é reportado por Silva (2010) na comunidade Pau Arrastado, zona rural de Campo Maior/PI e contrastando com o observado por Chaves e Barros (2012). Maioli-Azevedo e Fonseca-Kruel (2007), destacaram que as categorias de uso que apresentam maiores valores de consenso merecem estudos mais aprofundados das espécies e usos adotados, pois apresentam relevante importância cultural.

Alimentícia - Representada por 68 espécies, destacando-se as famílias Arecaceae (6), Anacardiaceae (5) e Cucurbitaceae (5), como as mais representativas. Com relação a maior representatividade da família Arecaceae, encontrada nesta categoria, pode ser explicada devido ao fato da comunidade encontrar-se inserida numa área de grande ocorrência de plantas dessa família, numa região de babaçuais e carnaubais. As espécies feijão (Phaseolus vulgaris L.), arroz (Oryza sativa L.), milho (Zea mays L.), mandioca (Manihot esculenta Crantz), macaxeira (Manihot utilíssima Pohl.), abóbora (Cucurbita pepo L.), quiabo (Abelmoschus esculentus Moench) e melancia (Solanum palinacanthum Dunal) se destacaram como os principais cultivos agrícolas. Destaca-se como a segunda categoria mais citada com 45,3\% do total, provavelmente devido ao costume local do cultivo de espécies comestíveis nas roças e nos quintais da maioria dos moradores da comunidade, pois esta é caracterizada pela agricultura de subsistência, com revenda apenas do excedente da produção. Fato similar se verifica em outros munícipios do Estado (Oliveira et al. 2010, Aguiar e Barros 2012), no Nordeste brasileiro (Roque e Loiola 2013; Leite e Marinho 2014) outras regiões do país (Schardong e Cervi 2000, Pasa et al. 2005, Silva eProença 2008). Essa atividade é conhecida historicamente como a atividade que tem garantido a sobrevivência das populações de comunidades rurais ao longo dos séculos.

A categoria apresentou uma quantidade significativa de plantas exóticas (41 espécies), com destaque para as 
hortaliças como coentro (Coriandrum sativum L.), cebolinha (Allium schoenoprasum L.), pimentão (Capsicum annuum L.) e pimenta-de-cheiro (Capsicum chinense Jacq.) que são cultivadas principalmente nos quintais em hortas e canteiros erguidos, estes últimos constituem-se como uma particularidade das comunidades piauienses. Fato também destacado no estudo realizado por Silva (2010) nas comunidades Resolvido, Pau-Arrastado e Salinas em Campo Maior/PI. A maioria dos moradores exerce essa atividade basicamente para consumo e, em alguns casos, para comercialização, configurando-se como uma como forma alternativa de complementar a renda.

Mais da metade das espécies encontradas são frutíferas (57\%) e cultivadas nos quintais das residências. Dentre as nativas, destacam-se pela ocorrência na maioria dos quintais de Anacardium occidentale L. (caju), goiaba (Psidium guajava L.), Carica papaya L. (Mamão), Spondias purpurea L. (Siriguela), no entanto, apenas o caju foi a espécie em comum ao estudo realizado por Florentinoet al. (2007) e Freitas et al. (2012). Dentre as exóticas destacam-se Mangifera indica L. (manga), Citrus aurantium L. (laranja), Malpighia glabra L. (acerola), Musa paradisiaca L. (banana) e Cocos nucifera L. (coco-da-praia). Para Carli et al. (2009) o consumo de frutas é um dos elementos que demonstram como as famílias rurais observam a passagem do tempo, privilegiando em seu cardápio cotidiano o tempo das coisas.

Ornamental - foram levantadas 30 espécies, distribuídas em 18 famílias botânicas. Apocynaceae (6) foi a que apresentou o maior número de espécies, seguida de Cactaceae (3). O hábito de cultivar plantas para ornamentar os ambientes domésticos como jardins e quintais representa uma atividade muito presente, visto que é comum observamos esta prática por toda comunidade. Nesse aspecto, os dados diferem dos obtidos por Franco e Barros (2006) no Quilombo Olho D'água dos Pires/ PI, que relatam ser esta uma atividade pouco desenvolvida na comunidade por elas pesquisada. Nessa categoria o status exótico foi superior $(63,4 \%)$ ao nativo $(36,6 \%)$ e geralmente as espécies são adquiridas de vizinhos, parentes e amigos. As citações totalizaram $100 \%$ dos entrevistados entre as mulheres, provavelmente por serem estas as mantenedoras e cuidadoras dos quintais e jardins, como já mencionado por Sablayioles (2004) e Aguiar (2009).

Nessa categoria as espécies que mais se destacaram embelezando as residências da comunidade foram: Rosa chinensis (rosa), Nephrolepis exaltata Schott (samambaia-de-metro), Azadirachta indica A. Juss. (ninho), Hibiscus rosasinensis L. (margarida), Catharanthus roseus (L.) G. Don (boa-noite) e Dieffenbacbia picta (comigo-ninguém-pode), esta última também bastante citada na categoria místico-religiosa.

Construção - representada por 15 espécies, em nove famílias botânicas, destas as que se destacaram com maior número de espécies foram Arecaceae (6) seguida por Leguminosae (5). Ressalta-se para essa categoria o uso exclusivamente de espécies nativas, corroborando com Borges e Peixoto (2009) e Silva (2010), demonstrando que as populações rurais detêm um vasto conhecimento acerca de plantas utilizadas na feitura de casas, cercas e portões.

As espécies que se destacaram de maneira significativa foram babaçu (Attalea speciosa Mart. ex Spreng.) e carnaúba (Copernicia prunifera (Mill.) H.E.Moore), na construção civil. A utilização dessas espécies ocorre principalmente com o uso das palhas do babaçu na cobertura de casas e o caule da carnaúba como sustentáculo para paredes e coberturas dessas construções (casas, banheiros, latadas, portões), fato verificado também por Gonzalez-Perez et al. (2012) na Terra Indígena Las Casas/PA. Copernicia prunifera foi citada para confecção de madeiramento para construção por Vieira et al. (2008), Chaves e Barros (2008) e Oliveira (2009) nas comunidades por eles estudadas no estado do Piauí. Na construção das cercas e cercadinhos de proteção de plantas, além da utilização dos talos do babaçu, verifica-se ainda a presença da espécie unha-de-gato (Mimosa caesalpinifolia Benth.). 
Para confeccionar e realizar reparos de canoas e instrumentos de pesca são utilizadas as espécies: Cedrobranco (Cardiospermum anomalum Cambess), Pequi (Caryocar coriaceum Wittm.), Pau-d'arco (Handroanthus serratifolius (Vahl) S.O. Grose). Resultados semelhantes foram destacados por Amorim (2010) no bairro Poty Velho em Teresina/PI e Santos (2012) em União/PI. Quanto ao uso do Pau-d'arco corrobora ainda o encontrado por Borges e Peixoto (2009) numa comunidade caiçara do litoral sul do Rio de Janeiro. Outras espécies que merecem destaque nessa categoria são: angelim (Andira retusa Humb., Bonpl. e Kunth), e aroeira (Myracrodruon urundeuva Allemão).

Forrageira - Nessa categoria foram levantadas nove espécies, representando $6 \%$ do total e distribuídas em seis famílias. A família que contribui com maior número de espécies foi Arecaceae (6), seguida da família Poaceae (2), que foi destacada por Oliveira et al. (2009) e Vieira (2009) como importantes nessa categoria. Do total de espécies levantadas 55\% são nativas, destacando-se mata-pasto (Senna obtusifolia L.) ecaju(Anacardium occidentale L.).

A espécie que apresentou maior número de citações foi o milho (Zea mays L.) que é utilizada na alimentação de aves, bovinos, caprinos e suínos criados por alguns moradores. A utilização dessa espécie para alimentação desses animais provavelmente esteja relacionada ao fato de que é uma das mais cultivadas na comunidade e o excedente da produção agrícola é armazenado para essa finalidade. Outra espécie que foi destacada nessa categoria foi Mimosa caesalpinifolia Benth. (unha-de-gato), também referida por Vieira (2009) no Quilombo dos Macacos em São Miguel do Tapuio/PI.

Místico-religiosa - Essa categoria foi representada por oito espécies, distribuída em seis famílias botânicas. Dentre elas, Euphorbiaceae foi a que mais se destacou em número de espécies (2), ficando as demais famílias representadas por apenas uma espécie. Foram indicadas no uso de rezas para defesa e contra quebrantos e mauolhado as seguintes espécies: Justicia pectoralis var. stenophylla Leonard (trevo), Sansevieria trifasciata Prain (espada-desão Jorge), Dieffenbachia picta (Lodd) Schott (comigo-ninguém-pode), Jatropha gossypiifolia L. (pião-roxo), Jatropha ribifolia (Pohl) Baill. (pião-branco), Ruta graveolens L. (arruda), Scoparia dulcis L. (vassourinha) e Capsicum frutescens L. (pimenta-malageta). Apesar do pouco número de espécies citadas, a prática de uso de plantas nesta categoria caracteriza-se como recorrente na comunidade, visto que a maioria $(61,5 \%)$ dos atores entrevistados citou algum tipo de ritual ou alguma forma de uso de plantas para cura ou defesa. Albuquerque (2005) indica que a conexão entre pessoas e plantas não se dá somente no nível médico ou terapêutico, mas também em nível mágico-religioso. As plantas que mais se destacaram na realização desses rituais foram: vassourinha. peão-roxo e comigo-ninguém-pode, corroborando com Pasa e Guarim Neto (2005) no Mato Grosso, Silva e Andrade (2005), Oliveira e Trovão (2009), Almeida e Bandeira (2010) e Roque et al. (2013) na região Nordeste, demonstrando a forte influência africana em todo o país.

$\mathrm{Na}$ comunidade residem oito rezadores que praticam esses rituais utilizando um pequeno galho da primeira planta mencionada passando sobre o corpo da pessoa acompanhado de uma reza, sendo usada principalmente para tirar quebranto e mal olhado. Fato verificado também por Oliveira e Trovão (2009) no agreste Paraibano. Somente as duas últimas plantas foram citadas para afugentar mau olhado, as quais são geralmente cultivadas em frente às casas, fato observado como prática recorrente em comunidades piauienses. Tal prática foi verificada por Sousa (2010) e Silva (2010) nas comunidades por elas pesquisadas.

Produção energética - Nesta categoria foram levantadas sete espécies nativas, distribuídas em quatro famílias e seis gêneros, representando 4,6\% do total de espécies pesquisadas. Destacou-se a família Leguminosae 
(3) com maior representatividade de espécies, porém o babaçu (Attalea speciosa Mart. ex Spreng) é a espécie mais empregada na produção de carvão que é feito principalmente da casca do coco, já que esta palmeira apresenta-se bastante acessível na comunidade. Esta produção de carvão configura-se como uma realidade muito difundida em território piauiense, como constatado também por Franco e Barros (2006) no Quilombo Olho D’agua dos Pires/PI. Outra alternativa, em menor escala, é a produção de carvão a partir das seguintes espécies: unhade-gato (Mimosa caesalpinifolia Benth.), catinga-branca (Combretum duarteanum Cambess.) mufumbo (Combretum leprosum Mart.) e mororó (Baubinia ungulata L.).

Os biocombustíveis apresentam-se como a principal fonte de energia para um grande contingente da população do mundo, especialmente em comunidades rurais dos países em desenvolvimento. No Brasil, sobretudo na região Nordeste esta realidade é mais frequente principalmente nas áreas de Caatinga onde ocorre grande extração de lenha e carvão para a cocção de alimentos. (Abbot e Lowore 1999, LI et al. 2005).

A prática da produção de carvão é comum mesmo entre os moradores que dispõem de fogão a gás. Estudos realizados por Perez-Negron e Casas (2007) no México, Ventura-Aquino et al. (2008) na África do Sul e Vieira (2010), confirmaram que a presença de fogões a gás em residências não substituem ou diminuem a importância do carvão. Em Maputo, Moçambique , Brouwer e Falcão (2001) afirmam que esta combinação de duas fontes de combustível funciona como uma estratégia para reduzir a despesa das famílias, fato também verificado por Ramos e Albuquerque (2012) em Cachoeira e Barrocas, comunidades rurais localizadas no município de Soledade/PB. Esta prática, em Novo Nilo apresenta-se ainda como uma forma rentável, pois o excedente desse carvão produzido, em alguns casos, é comercializado na própria comunidade. Alguns estudos demonstram a contribuição de elementos culturais para a continuação desta prática, especialmente quando os entrevistados indicam uma preferência por alimentos cozidos em fornos a lenha (Cocks, Wiersum 2003, Ventura-Aquino et al. 2008).

Artesanal - nesta categoria foram incluídas apenas três espécies, representando $2 \%$ do total indicado, nativas e pertencentes à família Arecaceae: Attalea speciosa Mart. ex Spreng (babaçu), Copernicia prunifera (carnaúba) e Astrocaryum vulgare Mart. (tucum). No que se refere ao uso dessas espécies, a palha da carnaúba foi citada como a parte mais usada para a fabricação dos seguintes artefatos: abano, bolsa, cesta, chapéu, corda, esteira, peneira, tapete e vassoura. Enquanto o babaçu, citado apenas para a fabricação de vassouras a partir do pecíolo de suas folhas e o tucum citado para fabricação de cordas. Os produtos confeccionados a partir dessas espécies, além de muito utilizados pelas comunidades locais, são comercializados nos municípios circunvizinhos e na capital.

No Piauí, Santos (2008), Aguiar (2009), Oliveira (2009), Amorim (2010), Silva et al. (2012) e Sousa (2012) entre outros, destacaram em suas pesquisas etnobotânicas a importância dessas palmeiras confirmando os diferentes estudos desenvolvidos no território brasileiro (Rufino et al. 2008, Nascimento 2009, Souza et al. 2011, Silva 2012) e em outras partes do mundo (Barfod e Balslev 1988, Moraes et al.1995; Borchseniuse BlicherMathiesen 1996; Moraes 2006, 2007; Gonzalez-Perez et al. 2012).

\section{Valor de uso}

No que concerne aos resultados referentes ao índice Valor de Uso, a espécie que apresentou maior valor foi o babaçu (Attalea speciosa Mart. ex Spreng com VU=3,6, seguida da carnaúba (Copernicia prunifera) com $\mathrm{VU}=1,96$, resultado similar ao verificado por Vieira (2008) para essa última espécie, que encontrou VU=1,95 
na comunidade por ele estudada. No entanto, merecem destaque ainda, por apresentarem valores significativos, os resultados referentes às espécies Mangifera indica L. (VU=0,70), Citrus aurantium L. (VU=0,58), e Malpighia glabra L. (VU=0,55), consideradas importantes na categoria alimentícia.

Na categoria medicinal destacou-se Lippia alba (Mill.) N. E. Br., espécie citada como calmante e como hipotensora, com $\mathrm{VU}=0,57$, justificando a concordância verificada entre os entrevistados para as indicações relativas ao tratamento das doenças do sistema nervoso nos resultados referentes ao índice de consenso dos informantes da comunidade. Friedman et al. (1986) sugerem que um bom critério para justificar o uso de uma planta é verificar a concordância de uso na comunidade, ou seja, quanto maior for esta concordância, é possível que a planta citada contenha algum composto químico que valide seu uso. As atividades calmante e hipotensora foram comprovadas por Matos (1999) e referidos por Mattos et al. (2007), quando afirmam que esta espécie vem sendo utilizada em diversos programas de fitoterapia, sendo largamente utilizada no Brasil devido às propriedades calmante, espasmolítica suave, analgésica, sedativa, ansiolítica e levemente expectorante. Esses efeitos são validados quimicamente por seus constituintes ativos, dentre eles o óleo essencial que apresenta citral, mirceno, limoneno e carvona e que, cuja concentração varia conforme o clima e a forma de cultivo (Lorenzi e Matos 2002). Julião et al. (2003) destacam o linalol com efeito depressor sobre o sistema nervoso central, resultando em propriedades hipnóticas, hipotérmicas e anticonvulsivantes.

O índice de Valor de Uso das espécies mostra o quão importante cada uma delas é para a comunidade estudada, apresentando-se como relevante argumento para a promoção da conservação destas em seus ambientes naturais.

\section{Espécies da flora utilizadas na geração de renda}

Muitas espécies apresentam potencial de uso econômico, sendo referidos pelos moradores como alternativa rentável que auxiliam nas despesas do orçamento familiar. Essas espécies estão distribuídas nas mais distintas categorias e são obtidas em diferentes locais, sendo algumas cultivadas e outras extraídas das matas mais

próximas. Na categoria alimentícia destacam-se as seguintes espécies: feijão (Phaseolus vulgaris), arroz (Oryza sativa), milho (Zea mays), mandioca (Manihot esculenta), macaxeira (Manihot utilissima), abóbora (Cucurbita pepo), quiabo (Abelmoschus esculentus), e melancia (Solanum palinacanthum) que são obtidas nos plantios de roçados e vazantes e vendidas, quando há excedente na produção, dentro da comunidade ou nas cidades circunvizinhas. Outras espécies como: batata-doce (Ipomoea batatas), banana (Musa paradisiaca), coentro (Coriandrum sativum), cebolinha (Allium schoenoprasum), pimentão (Capsicum annuum) e pimenta-de-cheiro (Capsicum chinense), são cultivadas em pequenas hortas ou canteiros erguidos nos quintais e vendidas geralmente para estabelecimentos comerciais. Na categoria medicinal destacam-se como espécies utilizadas na produção de garrafada: penicilina (Alternanthera dentata), bredo (Amaranthus deflexus), perpeta (Gomphrena globosa), aroeira (Myracrodruon urundeuva), chanana (Turnera ulmifolia), ameixa (Ximenia americana), açoita-cavalo (Luehea speciosa), aroba (Neptunia plena), embaúba (Cecropia glaziovi), e milindro (Asparagus sp), sendo algumas cultivadas nos quintais e outras obtidas nas matas dos arredores da comunidade. As palmeiras babaçu, carnaúba e tucum são destaque nas categorias de artesanato e construção. Sendo o babaçu utilizado ainda, na produção de azeite vegetal aproveitado para fins alimentício e medicinal, configurando-se com grande potencial econômico para a comunidade. Outra alternativa geradora de renda realizada por apenas um morador é a fabricação e reparo de canoas utilizando as seguintes 
espécies: unha-de-gato (Mimosa caesalpinifolia), catinga-branca (Combretum duarteanum) mufumbo (Combretum leprosum), mororó (Baubinia ungulata), cedro-branco (Cardiospermum anomalum), pequi (Caryocar coriaceum), e paud'arco (Handroanthus serratifolius), angelim (Andira retusa) e aroeira (Myracrodruon urundewva).

As espécies nativas destacaram-se de forma exclusiva nas categorias construção, artesanal e produção energética, enquanto as exóticas são usadas principalmente nas categorias medicinal e alimentícia, havendo uma vasta quantidade de espécies utilizadas para geração de renda, demonstrando que a comunidade retira da terra seu sustento. Os moradores da comunidade conhecem e usam as espécies mais necessárias à sobrevivência e as mulheres apresentam-se como membros de significativa importância na manutenção da vegetação local. A maioria das espécies é especialmente útil e o saber popular deve ser resgatado e mantido por meio de ações desenvolvidas pelas entidades responsáveis pela gestão da comunidade, para que não haja aculturamento.

\section{REFERÊNCIAS}

Abbot P e Owore J. 1999. Characteristics and management potential of some indigenous firewood species from Malawi. Forest Ecology and Management, 119:111-21.

Agra MF, Freitas PF e Barbosa-Filho JM. 2007. Synopsisof the plants known as medicinal and poisonous in Northeast of Brazil.Revista Brasileira de Farmacognosia, 17 (1): 114-140.

Aguiar LCGG. 2009. Etnobotânica em quintais de comunidades rurais no domínio do cerrado Piauiense (Munícipio de Demerval Lobão, Piauí, Brasil). 112p. Dissertação (Mestrado) - Programa de Pós-Graduação em Desenvolvimento e Meio Ambiente. Universidade Federal do Piauí, Teresina, 2009.

Aguiar LCGG e Barros RFM. 2012. Plantas medicinais cultivadas em quintais de comunidades rurais no domínio do cerrado piauiense (Município de Demerval Lobão, Piauí, Brasil). Revista Brasileira de Plantas Medicinais, v. 14, n.3, p.419-434.

Albertasse LD, Thomaz LD e Andrade MA. 2010. Plantas medicinais e seus usos na comunidade da Barra do Jucu, Vila Velha, ES. Revista Brasileira de Plantas Medicinais, v.12, n.3, p. 250-260.

Albuquerque UP, Lucena RFP e Cunha LVFC..2010. Métodos e Técnicas na Pesquisa Etnobiológica e Etnoecológica. 1. ed. Recife: NUPEEA, 559p.

Albuquerque UP e Andrade LHC. 2002. Conhecimento botânico tradicional e conservação em uma área de caatinga no Estado de Pernambuco, Nordeste do Brasil. Acta Botânica Brasílica, n.16, p.273-85.

Albuquerque UP. 2005. Introdução à Etnobotânica. 2. ed. Rio de Janeiro: Editora Interciência. 93p.

Albuquerque UP, Silva JS, CamposJLA, Sousa RS, Silva TCe Alves RRN. 2013. The current status of ethnobiological research in Latin America: gaps and perspectives. Journal of Ethnobiology and Ethnomedicine. 9:72.

Almeida DG. 2000. A construção de sistemas agroflorestais a partirdo saber ecológico local: o caso dos agricultores familiares que trabalham com agrofloresta em Pernambuco. 235 p. Dissertação (Mestrado em Agro ecossistemas) - Centro de Ciências Agrárias. Universidade Federalde Santa Catarina, Florianópolis, 
2000.

Almeida VS e Bandeira FPSF. 2010. O significado cultural do uso de plantas da caatinga pelos quilombolas do Raso da Catarina, município de Jeremoabo, Bahia, Brasil. Rodriguesia, 61(2): 195-209.

Alves RRN, Silva AAG, Souto WMS e Barboza RRD. 2007. Utilização e comércio de plantas medicinais em Campina Grande, PB, Brasil. Revista Eletrônica de Farmácia, 4(2): 175-198.

Amaral CN e Guarim Neto G. 2008. Os quintais como espaços de conservação e cultivo de alimentos: um estudo na cidade de Rosário Oeste (Mato Grosso, Brasil). Boletim do Museu Paraense Emílio Goeldi. Ciências Humanas 3 (3): 329-341.

Amorim AN. 2010. Etnobiologia da comunidade de pescadores artesanais urbanos do bairro Poti Velho, Teresina/PI, Brasil.122p. Dissertação (Mestrado em Desenvolvimento e Meio Ambiente) - Universidade Federal do Piauí, Teresina, 2010.

Amorozo MCM. 2012. Uso e diversidade de plantas medicinais em Santo Antônio do Laverger, MT, Brasil. Acta Botânica Brasilica, v.16, n. 2, p. 189-203.

Amorozo MCM, Ming LC, Silva SMP(Eds). 2002. Métodos de coleta e análise de dados em Etnobiologia e etnoecologia e disciplinas correlatas. UNESP/CNPq, Rio Claro.

Bailey K. 1994. Methods of social research.4.ed. New York: The Free Press, 588 p.

Baldauf C, Kubo RR, Silva F e Irgan BE. 2009. "Ferveu, queimou o ser da erva”: conhecimentos de especialistas locais sobre plantas medicinais na região Sul do Brasil. Revista Brasileira de Plantas Medicinais, Botucatu, v.11, n.3, p.282-291.

Barbeta PA. 2006. Estatística aplicada as Ciências Sociais. 6. Ed. Editora da UFSC.

Barfod A e Balslev H. 1988. The use of palms by the cayapas and Coiaqueres on the coastal plain of Ecuador. Principes. v. 32. p. 29-42.

Beck HT e Ortiz A. 1997. Proyecto etnobotánico de la comunidad Awá en el Ecuador. Pp. 159-176. In: M. RIOS e H.B. PEDERSEN (eds.). Uso y Manejo de Recursos Vegetales. Memorias del II Simposio Ecuatoriano de Etnobotánica y Botánica Economica, Quito.

Begossi A, Hanazaki N e Ramos RM. 2004. Food chain and the reasons for fish food taboos among Amazonian and Atlantic Forest fishers (Brazil). Ecological Applications, v. 14, n.5, p. 1334-1343.

Begossi A, Hanazaki N. e Tamashiro JY. 2002. Medicinal plants and the Atlantic Forest (Brazil): knowledge, use and conservation. Human Ecology. v. 30. p. 281-299.

Bernard HR. 1988. Research in cultural anthropology. Sage. Newbury Park, CA, EEUU. 520 pp.

Borges R e Peixoto AL. 2009. Conhecimento e Uso de Plantas em uma Comunidade Caiçara do Litoral Sul do Estado do Rio de Janeiro, Brasil. Acta Botânica Brasílica, v. 23, n. 3, p. 769-779. 
Brouwer R e Falcão MP. 2004. Wood fuel consumption in Maputo, Mozambique. Biomass and Bioenergy, v. 27, n. 3, p. 233-245.

Carli AP, Terme CM, Souza GC, Bassi JB, Luz LF, Ramos MO e Kubo RR. 2009. Perspectivas no registro de saberes e práticas relacionados à agricultura, alimentação e artesanato em comunidade rural no Litoral Norte do RS.

Carniello MA, Silva RS, Cruz MAB e Guarim Neto G. 2010. Quintais urbanos de Mirassol D’Oeste-MT, Brasil: uma abordagem etnobotânica. Acta Amazônica, Manaus, v. 40, n.3, p. 451-470.

Carvalho JSB, Martins JDLM, Mendonça MCS e Lima LD. 2013. Uso popular das plantas medicinais na comunidade da várzea, Garanhuns-PE. Revista de Biologia e Ciências da Terra, Campina Grande, v. 13, n. 2, p. 58-65.

Ceolin T, Heck RM, Barbieri RL, Schwartz E, Muniz RM e Pillon CN. 2011. Plantas medicinais: transmissão do conhecimento nas famílias de agricultores de base ecológica no Sul do RS. Revista da Escola de Enfermagem da USP, v.45, n.1, p. 47.

CEPRO. 2011. Piauí em números. Centro de Pesquisa Econômicas e Sociais do Estado do Piauí - CEPRO - PI. 8. ed.

Chaves EMF e Barros RFM. 2012. Diversidade e uso de recursos medicinais do carrasco na APA da Serra da Ibiapaba, Piauí, Nordeste do Brasil. Revista Brasileira de Plantas Medicinais (Impresso), v. 14, p. 476-486.

Chaves MF e Barros RFM. 2008. Resource use of the flora of the brushwood vegetation in Cocal Country, Piauí, Brasil.Functional Ecosystems e Communities, v. 2, p. 51-58.

Cocks ML e Wiersum KF. 2003. The significance of plant diversity to rural households in Eastern Cape province of South Africa. Forests, trees and livelihoods, v. 13, p. 39-58.

Coelho-Ferreira M. 2009. Medicinal knowledge and plant utilization in na Amazonian coastal community of Marudá, Pará State (Brazil), Journal of ethnophamarcology. v. 126, p. 159-175.

Costa VP e Mayworm MAS. 2011. Plantas medicinais utilizadas pela comunidade do bairro dos Tenentes município de Extrema, MG, Brasil. Revista Brasileira de Plantas Medicinais, Botucatu, v.13, n.3.

Cotton CM. 1996. Ethnobotany: principles and applications. England: Britain Library.

Crepaldi MOS e Peixoto AL. 2010. Use and knowledge of plants by "Quilombolas" as subsidies for conservation efforts in an area of Atlantic Forest in Espírito Santo State, Brazil. Biodiversity and Conservation, 19: 37-60.

Cronquist A. 1981. An integrated system of classification of flowering plants. New York: Columbia Universaty Press 1262 p.

De-la-cruz H, Vilcapoma G e Zevallos PA. 2007. Ethnobotanical study of medicinal plants used by the Andean people of Canta, Lima, Peru. Journal of Ethnopharmacology. v. 111. p. 284-294.Disponível em:<http:// 
www.ufrgs.br/pgdr/arquivos/637.pdf>. Acesso em: 26 ago. 2012.

Figueiredo GM, Leitão-Filho H e Begossi A. 1993. Ethnobotany of Atlantic Forest Coastal Communities: diversity of plant uses in Gamboa (Itacuruça Island, Brazil). Human Ecology 2 (4): 419-430.

Florentino, ATN.; araujo, E.L. \& albuquerque, U.P. 2007. Contribuição de quintais agroforestais na conservação de plantas da Caatinga, município de Caruaru, PE, Brasil. Acta Botânica Brasílica, 21(1): 37-47.

Fonseca-kruel VS e Peixoto AL. 2004. Etnobotânica na Reserva Extrativista Marinha de Arraial do Cabo, RJ, Brasil. Acta Botânica Brasílica18: p.177-190.

Franco, EAPA. e Barros, RFM. 2006. Uso e diversidade de plantas medicinais no Quilombo olho D'água dos Pires, Esperantina, Piauí. Revista Brasileira de Plantas Medicinais, v. 8, n. 3. p. 78-88.

Freitas ST, Pamplin PAZ, Legat J, Fogaça FHS e Barros RFM. 2012. Conhecimento tradicional das marisqueiras de Barra Grande, Área de Proteção Ambiental do Delta do Rio Parnaíba, Piauí, Brasil. Revista Ambiente \& Sociedade,v. 15, n. 2, p. 91-110.

Friedman J, Yaniv Z, Dafni A e Palewitch D. 1986. A preliminary classification of the healing potential of medicinal plants based on a rational analysis of an ethnopharmaco-logical field survey among Bedouins in the Negev Desert, Israel. J. Ethnopharmacol. 16: 275-287.

Gandolfo ES e Hanazaki N. 2011. Etnobotânica e urbanização: conhecimento e utilização de plantas de restinga pela comunidade nativa do Distrito do Campeche (Florianópolis, SC). Acta Botânica Brasílica, v. 25, p. 168177.

González-Pérez SE, Coelho-Ferreira M, Robert P e Garcés CL L. 2012. Conhecimento e usos do babaçu (Attalea speciosa Mart. ex Spreng e Attalea eichleri (Drude) A. J. Hend.) entre os Mebêngôkre-Kayapó da Terra Indígena Las Casas, estado do Pará, Brasil.Acta Botânica Brasilica. vol. 26 nº.2.

Guarim-Neto G, Santana SR e Silva JVB. 2000. Notas etnobotânicas de espécies de Sapindaceae Jussieu. Acta Botânica Brasílica, 14(3): 327-334.

Hanazaki, N, Castro F, Oliveira VG, Peroni N. 2007. Between the sea and the land: the livelihood of estuarine people in southeastern Brazil. Ambiente e Sociedade (Campinas), v. 10, p. 121-136.

IBGE. Instituto Brasileiro de Geografia e Estatística. 2010. Disponível em: < http://www.ibge.gov.br/ cidadesat/topwindow.htm?1> acesso em 20 de junho de 2012.

Judd WS, Campbell CS, Kellogg EA e Stevens PF. 1999. Plant systematics: a phylogenetic approach. Sunderland: Sinauer Associates. 464 p.

Julião LS, Tavares ES, Lage CLS e Leitão SG. 2003. Cromatografia em camada fina de extratos de três quimiotipos de Lippia alba (Mill) N. E. Br. (erva-cidreira). Revista Brasileira de Farmacognosia, v.13, p.36-38.

Leite IA e Marinho MGV. 2014. Levantamento etnobotânico de plantas medicinais em comunidade indígena no 
município de Baía da Traição- PB. Biodiversidade - V.13, N1, p. 82.

Li, Z, Tang R, Xia C, Luo H e Zhong H. 2005. Towards green rural energy in Yunnan, China. Renewable Energy. 30 (2):99-108.

Lima RX, Silva SM, Kuniyoshi YS e Silva LB.. 2000. Etnobiologia de comunidades continentais da Área de Proteção Ambiental de Guaraqueçaba - Paraná - Brasil. Etnoecologica4: 33-54.

Lopes LCM e Lobão AQ. 2013. Etnobotânica em uma comunidade de pescadores artesanais no litoral norte do Espírito Santo, Brasil. Boletim do Museu de Biologia Mello Leitão, 32: 29-52.

Lorenzi H e Matos FJA. 2002. Plantas medicinais no BrUasil: nativas e exóticas cultivadas. Nova Odessa, São Paulo, Instituto Plantarum.

Lucena RFP, Medeiros PM, Araújo EL, Alves AGC e Albuquerque UP. 2012. The ecological apparency hypothesis and the importance of useful plants in rural communities from Northeastern Brazil: An assessment based on use value. Journal of Environmental Management, v. 96, n. 1, p. 106-115, 2012.

Maioli-azevedo V e Fonseca-Kruel VS. 2007. Plantas medicinais e ritualísticas vendidas em feiras livres no município do Rio de Janeiro, RJ, Brasil: estudo de caso nas zonas Norte e Sul. Acta Botânica Brasílica, v.21, n.2, p.263-75.

Marinho MGV, Silva CC e Andrade LHC. 2011. Levantamento etnobotânico de plantas medicinais em área de caatinga no município de São José de Espinharas, Paraíba, Brasil. Revista Brasileira de Plantas Medicinais, Botucatu,v.13, n.2, p. 170-182.

Matos FJA. 1999. Plantas da medicina popular do Nordeste. Fortaleza: Edições UFC, 80p.

Mattos SH, Innecco R, Marco CA e Araújo AV. 2007. Plantas medicinais e aromáticas cultivadas no Ceará: tecnologia de produção e óleos essenciais. Fortaleza: Banco do Nordeste do Brasil, p. 61-63. (série BNB Ciência e tecnologia 2).

Merétika AHC, Peroni N e Hanazaki N. 2010. Local knowledge of medicinal plants in three artisanal fishing communities (Itapoá, Soutervan Brazil), according to gender, age, and urbanization. Acta Botânica Basílica. 24: 386-394.

Moraes MR. 2006. La flora de palmeras de Bolivia en un contexto neotropical. Arnaldoa. v.13, p.348-359.

Moraes MR. 2007. Phytogeographical Patterns of BolivianPalms. Palms. v.51, p.177-186.

Moraes MR, Sarmiento \& J. e Oviedo E. 1995. Richness and uses in a diverse palm site in Bolivia. Biodiversity and Conservation. v.4, p. 719-727.

Moraes MR, Borchsenius F e Blicher-mathiesen U. 1996. Notes on the Biology and uses of the motacú palm (Attalea phalerata, Arecaceae) from Bolivia. Economic Botany. v. 50, p. 423- 428.

Mori AS, LA Mattos-silva, G Lisboa e L Coradin. 1989. Manual de manejo do herbário fanerogâmico. 
Ilhéus. Centro de Pesquisa do Cacau, 104 p.

Mosca VP e Loiola MIB. 2009. Uso popular de plantas medicinais no Rio Grande do Norte, Nordeste do Brasil. Revista Caatinga, v.22, p.225-234.

Nascimento ART. 2009. Riqueza e etnobotânica de palmeiras no território indígena krahô, Tocantins, Brasil. Floresta. v. 40, p. 209-220.

Oliveira ECS e Trovão DMBM. 2009. O uso de plantas em rituais de rezas e benzeduras:um olhar sobre esta prática no estado da Paraíba. Revista Brasileira de Biociências, v. 7, n. 3, p. 245-251.

Oliveira ER e Menini Neto L. 2012. Levantamento etnobotânico de plantas medicinais utilizadas pelos moradores do povoado de Manejo, Lima Duarte - MG. Revista Brasileira de Plantas Medicinais, Botucatu, v.14, n.2, p. 311-320.

Oliveira FCS, Barros RFM e Moita Neto JM. 2010. Plantas medicinais utilizadas em comunidades rurais de Oeiras, semiárido piauiense. Revista Brasileira de Plantas Medicinais (Impresso), v. 12, p. 282-301.

Oliveira FC, Albuquerque UP, Fonseca-Kruel VS e Hanazaki N. 2009.Avanço nas pesquisas etnobotânicas no Brasil. Acta BotânicaBasílica, p. 590-605.

Oliveira FCS. 2009. Conhecimento botânico tradicional em comunidades rurais do semi-árido piauiense. Teresina UFPI. 101 p. Dissertação (Mestrado) - Programa de Pós Graduação em Desenvolvimento e Meio Ambiente. Universidade Federal do Piauí, Teresina. 2009.

Pasa MC. 2011. O saber local e a medicina popular: A etnobotânica em Cuiabá. Mato Grosso. Brasil. Boletim do Museu Paraense Emílio Goeldi. Ciências Humunas, Belém, v. 6, n. 1, p. 179-196.

Pasa MC e Guarim Neto G. 2005. Garrafadas medicinais de plantas de Mato Grosso (I): Anemopaegma arvense (Vell.) Stellf. e A. glaucum Mart. ex DC. Biodiversidade, v. 1, n. 4, p. 28-38.

Pasa MC, Soares JJ e Guarim Neto G. 2005. Estudo etnobotânico na comunidade de Conceição-Açu (alto da bacia do rio Aricá Açu, MT, Brasil). Acta Botanica brasilica, v. 19, n. 2, p. 195 - 207.

Pérez-Négron E e Casas A. 2007. Use, extraction rates and spatial availability of plant resources in the TehuácanCuicatlán Valley, Mexico: The Case of Santiago Quiotepec, Oaxaca. Journal of Arid Environments, v. 70, p. 356-379.

Phillips O e Gentry AH. 1993a. The useful plants of Tambopata, Peru: I. Statistical hypoteses tests with a new quantitative technique. Economic Botany 47(1): 15-32.

Phillips O e Gentry AH. 1993 b. The useful plants of Tambopata, Peru: II. Additional, hypothesis testing in quantitative ethnobotany. Economic Botany 47(1): 33-43.

Phillips O. 1996. Some quantitative methods for analyzing ethnobotanical knowledge. Em Alexiades MN (Ed.) Selected guidelines for ethnobotanical research: a field manual. The New York Botanical Garden. New 
York. pp. 171-197.

Pilla MAC e Amorozo MCM. 2009. O conhecimento sobre os recursos vegetais alimentares em bairros rurais no Vale do Paraíba, SP, Brasil. Acta Botânica Brasílica, v. 23, n. 4, p. 1190-1201.

Pilla MAC, Amorozo MCM e Furlan A. 2006. Obtenção e uso das plantas medicinais no distrito de Martim Francisco, Município de Mogi-Mirim, SP, Brasil. Acta Botânica Brasílica, v.20, p.789-802.

Ramos MA e Albuquerque UP. 2012. The domestic use of firewood in rural communities of the Caatinga: How seasonality interferes with patterns of firewood collectione. Biomas and Bioenergy, v.39, p.147-158.

Rondon Neto RM, Byczkovski A, Winnicki JA, Simao SMS e Pasqualotto TC 2004. Os quintais agroflorestais do assentamento rural rio da areia, município de Teixeira Soares, PR. Cerne, 10(1): 125-135.

Roque AA e Loiola MIB. 2013. Potencial de uso dos recursos vegetais em uma Comunidade rural no semiárido Potiguar. Revista Caatinga, v. 26, n. 4, p. 88 - 98.

Rosa LS, Silveira EL, Santos MM, Modesto RS, Perote JRS e Vieira TA. 2007. Os quintais agroflorestais em áreas de agricultores familiares no município de Bragança - PA: composição florística, uso de espécies e divisão de trabalho familiar. Revista Brasileira de Agroecologia, 2(2): 337-341.

Rossato SC. 1996. Uso de plantas do litoral norte do estado de São Paulo. Dissertação (Mestrado em Ciências Biológicas - Botânica). Departamento de Ecologia, IB/Universidade de São Paulo, São Paulo, 1996.

Rossato SC, Leitao-Filho HF, Begossi A. 1999. Ethnobotany of caiçaras of the Atlantic forest Coast (Brazil). Economic Botany 53 (4): 387-395.

Rufino MUL, Costa JTM, Silva VA e Andrade LHC. 2008.Conhecimento e uso do ouricuri (Syagrus coronata) e do babaçu (Orbignya phalerata) em Buíque, PE, Brasil. Acta Botânica Brasílica, v.4 p.1141-1149.

Sablayioles, MGP. 2004. Diversidade e uso de plantas em quintais ribeirinhos de Brasilia Legal - Aveiro, Pará (Brasil). Tese (Doutorado em Biologia Vegetal)- Universidade Federal de Pernambuco.

Santos LGP. 2008. Florística e conhecimento botânico tradicional em áreas de cerrado no município de Monsenhor Gil, Piauí, Brasil.Teresina UFPI. 101 p. Dissertação (Mestrado) - Programa de Pós Graduação em Desenvolvimento e Meio Ambiente. Universidade Federal do Piauí, Teresina., 2008.

Santos LGP, Barros RFM, Araújo, JLL e Vieira FJ. 2008.Diversity of useful plant resources in the city of Monsenhor Gil, Piauí State, Brazil. Functional Ecossystems and Comunities, v. 2, p. 72-80.

Schardong, RMF. e Cervi, AC. 2000. Estudos etnobotânicos das plantas de uso medicinal e místico na comunidade de São Benedito, bairro São Francisco, Campo Grande, MS, Brasil. Acta Biológica Paranaense 29(1/4): 187-217.

Silva AJR e Andrade LHC. 2005. Etnobotânica nordestina: estudo comparativo da relação entre comunidades e vegetação na Zona do Litoral - Mata do Estado de Pernambuco, Brasil. Acta Botanica Brasilica 19 (1): 45-60. 
Silva AJ, Barros RFM, Araújo, JLL. 2012. Reflexões sobre desenvolvimento local sustentável: extrativismo do coco babaçu [Orbignya speciosa (Mart. ex Spreng)] em Miguel Alves, PI. In: Rocha, JRS.; Barros, RFM.; Araujo, JLL. (Org.). Sociobiodiversidade no meio norte brasileiro. 1 ed. Teresina: EDUFPI, v. 7, p. 11-32.

Silva CSP e Proença CE. 2008. Uso e disponibilidade de recursos medicinais no município de Ouro Verde de Goiás, GO, Brasil. Acta Botânica Brasílica. 22(2): 481-492.

Silva MP. 2010. Conhecimento etnobotânico de comunidades rurais da Serra de Campo Maior - Piauí, Brasil. p.174. Dissertação (Mestrado em desenvolvimento e Meio Ambiente)- Universidade Federal do Piauí, 2010.

Simões CMO, Mentz LA, Schenkel EP, Nicolau M e Bettega JR. 1998. Plantas da Medicina Popular do Rio Grande do Sul. 5. ed. Porto Alegre: Editorada UFRGS, v.1. 150 p.

Sousa RS. 2010. Etnobotânica e etnozoologia de comunidades pesqueiras da Área de Proteção Ambiental (APA) do Delta do Parnaíba, Nordeste do Brasil.175p. Dissertação (Mestrado em Desenvolvimento e Meio ambiente) - Universidade Federal do Piauí, Teresina, 2010.

Sousa RS, Hanazaki N, Lopes JB e Barros RFM. 2012. Are Gender and Age Important in Understanding the Distribution of Local Botanical Knowledge in Fishing Communities of the Parnaíba Delta Environmental Protection Area. Ethnobotany Researchand Applications, v. 10, p. 151-159.

Souza MHSL, Monteiro CA, Figueredo PMS, Nascimento FRF e Guerra RNM. 2011. Ethnopharmacological use of babassu (Orbignya phalerata Mart) in communities of babassu nut breakers in Maranhão, Brazil. Journal of Ethnopharmacology, v.133, p. 1-5.

Souza LF. 2007. Recursos vegetais usados na medicina tradicional do Cerrado (comunidade de Baús, Acorizal, MT, Brasil). Revista Brasileira de Plantas Medicinais, v.9, n.4, p.44-54.

Trotter R e Logan M. 1986. Informant consensus: a new approach for identifying potentially effective medicinal plants. In: INDIGENOUS MEDICINE AND DIET: BIOBEHAVIORAL APPROACHES, Redgrave. Nova York. p. 91-11.

Ventura-Aquino Y, Rendon B, Rebollar S e hernandez G. 2008. " Use and conservation of forest resources in the municipality of San Agustin Loxicha, Sierra Madre del Sur, Oaxaca, Mexico.”Agroforestry Systems 73(3): 167-180.

Vieira FJ e Barros RFM. 2010. Comunidade quilombola e o uso dos recursos vegetais no Piauí. Sapiência (FAPEPI. Impresso), v. 25, p. 19-19.

Vieira FJ, Santos 1GP, Oliveira FCS, Oliveira LSD, Araujo JLL e Barros RFM. 2009. A Utilização dos Recursos Vegetais por Comunidade Quilombola no Piauí. In: Antonio Alberto Jorge Farias Castro; Jaíra Maria Alcobaça Gomes; Roseli Farias Melo de Barros. (Org.). Biodiversidade e Desenvolvimento do Trópico Ecotonal do Nordeste. 1 ed. Teresina: EDUFPI, v. 4, p. 213-232.

Vieira FJ, Santos LGP, Barros RFM e Araújo JLL. 2008. Quilombola of Macacos Community, São Miguel 
do Tapuio City, Piauí State: history, use and conservation of plant resources. Functional Ecossystems and Comunities, v.2, n.8, p.81-7.

Vieira TA, Rosa LS, Vasconcelos PCS, Santos MM e Modesto RS. 2007. Sistemas agroflorestais em áreas de agricultores familiares em Igarapé-Açu, Pará: caracterização florística, implantação e manejo. Acta Amazônica, 37(4): 549-558.

Winklerprins AMGA. 2002. House-lot gardens in Santarem, Para, Brazil: linking rural with urban. Urban Ecosystems, 6: 43-65.

Zuchiwschi E, Fantini AC, Alves AC e Peroni N. 2010. Limitações ao uso de espécies florestais nativas pode contribuir com a erosão do conhecimento ecológico tradicional e local de agricultores familiares. Acta Botânica Brasílica, v. 24, p. 270-282. 